Research

\title{
Mathematical modeling of laser lipolysis
}

Serge R Mordon*1, Benjamin Wassmer ${ }^{2}$, Jean Pascal Reynaud ${ }^{3}$ and

Jaouad Zemmouri²

Address: ${ }^{1}$ INSERM U 703 - IFR 114, Lille University Hospital, 59037 Lille, France, ${ }^{2}$ OSYRIS Lasers et Applications 121 Rue Chanzy, 59260 Hellemmes, France and ${ }^{3}$ Cemaform, 83000 Toulon, France

Email: Serge R Mordon* - mordon@lille.inserm.fr; Benjamin Wassmer - benjamin.wassmer@osyris.com; Jean Pascal Reynaud - jeanpascal.reynaud@wanadoo.fr; Jaouad Zemmouri - jaouad.zemmouri@osyris.com

* Corresponding author

Published: 29 February 2008

BioMedical Engineering OnLine 2008, 7:10 doi:10.1186/1475-925X-7-10
Received: 9 October 2007

Accepted: 29 February 2008

This article is available from: http://www.biomedical-engineering-online.com/content/7///10

(c) 2008 Mordon et al; licensee BioMed Central Ltd.

This is an Open Access article distributed under the terms of the Creative Commons Attribution License (http://creativecommons.org/licenses/by/2.0), which permits unrestricted use, distribution, and reproduction in any medium, provided the original work is properly cited.

\begin{abstract}
Background and Objectives: Liposuction continues to be one of the most popular procedures performed in cosmetic surgery. As the public's demand for body contouring continues, laser lipolysis has been proposed to improve results, minimize risk, optimize patient comfort, and reduce the recovery period. Mathematical modeling of laser lipolysis could provide a better understanding of the laser lipolysis process and could determine the optimal dosage as a function of fat volume to be removed.

Study design/Materials and Methods: An Optical-Thermal-Damage Model was formulated using finite-element modeling software (Femlab 3.I, Comsol Inc). The general model simulated light distribution using the diffusion approximation of the transport theory, temperature rise using the bioheat equation and laser-induced injury using the Arrhenius damage model. Biological tissue was represented by two homogenous regions (dermis and fat layer) with a nonlinear air-tissue boundary condition including free convection.

Video recordings were used to gain a better understanding of the back and forth movement of the cannula during laser lipolysis in order to consider them in our mathematical model. Infrared video recordings were also performed in order to compare the actual surface temperatures to our calculations. The reduction in fat volume was determined as a function of the total applied energy and subsequently compared to clinical data reported in the literature.
\end{abstract}

Results: In patients, when using cooled tumescent anesthesia, $1064 \mathrm{~nm}$ Nd:YAG laser or $980 \mathrm{~nm}$ diode laser: (6 W, back and forth motion: $100 \mathrm{~mm} / \mathrm{s})$ give similar skin surface temperature $\left(\max : 41^{\circ} \mathrm{C}\right)$. These measurements are in accordance with those obtained by mathematical modeling performed with a $1 \mathrm{~mm}$ cannula inserted inside the hypodermis layer at $0.8 \mathrm{~cm}$ below the surface. Similarly, the fat volume reduction observed in patients at 6-month follow up can be determined by mathematical modeling. This fat reduction depends on the applied energy, typically $5 \mathrm{~cm}^{3}$ for $3000 \mathrm{~J}$. At last, skin retraction was observed in patients at 6-month follow up. This observation can be easily explained by mathematical modeling showing that the temperature increase inside the lower dermis is sufficient $\left(48-50^{\circ} \mathrm{C}\right)$ to induce skin tightening

Discussion and Conclusion: Laser lipolysis can be described by a theoretical model. Fat volume reduction observed in patients is in accordance with model calculations. Due to heat diffusion, temperature elevation is also produced inside the lower reticular dermis. This interesting observation can explain remodeling of the collagenous tissue, with clinically evident skin tightening.

In conclusion, while the heat generated by interstitial laser irradiation provides stimulate lipolysis of the fat cells, the collagen and elastin are also stimulated resulting in a tightening in the skin. This mathematical model should serve as a useful tool to simulate and better understand the mechanism of action of the laser lipolysis 


\section{Introduction}

The subcutaneous fat layer, or hypodermis, bridges between the overlying dermis and the underlying body constituents. In most areas of the body this layer is relatively thick, typically in the order of several millimetres. However, there are areas of the body where pockets of excess fat can be observed: abdomen, hips, buttocks, thighs, knees, upper arms, chin, cheeks and neck. Liposuction is a procedure that can help sculpt the body by removing unwanted fat from these specific areas. Liposuction has become increasingly popular over the last decade and is now among the most popular body sculpting procedures. This increasing popularity is associated with the evolution of techniques and equipment for fat removal and body reshaping. Besides the traditional suctionassisted lipoplasty, other options include ultrasoundassisted and external ultrasound-assisted liposuction, power-assisted liposuction, and laser lipolysis. The efforts in the search for alternatives and new tools aim mainly at reducing downtime, decreasing operator effort for the surgeon and assistant, reducing bleeding and promoting skin tightening,

Laser lipolysis, also called laser lipoplasty has been has been described first in 1994 [1]. This technique is now widely used in Europe and Latin America, and has recently been introduced in Japan and the United States. Less trauma, bleeding and pain have been the main advantages of this technique [2].

After adequate infiltration of an anesthetic solution, a flexible fiber optic delivered through a small caliber cannula is inserted inside the fat tissue. The positioning of the $1 \mathrm{~mm}$ cannula is highlighted via trans-illumination from a red guiding beam. The laser energy is transmitted to the adipocytes, which absorb the energy, expand their volume, and rupture [3]. Histologic analyses of the effects of the Nd:YAG laser and of the continuous wave $980 \mathrm{~nm}$ laser diode on human fat tissue have shown areas of reversible cellular damage (tumefaction), irreversible tissue damage (lysis) and a reduced intensity of bleeding, as compared with the tissue products by conventional liposuction $[4,5]$.

The mechanisms leading to laser lipolysis are temperature dependent. First, for low energy and consequently low temperature, only tumefaction of the adipocytes is observed [4]. Using higher energy, the histological assessment carried out by Goldman on tissues removed immediately following the procedure showed the rupture of adipocytes but also the coagulation of small vessels in the fatty tissue. Since the heat is confined inside the adipocyte, it leads to the rupture of its membrane. The effect is not only thermal but also thermomechanical.
More importantly, the degree of tumefaction and lysis varied proportionally with the intensity of energy accumulated to the target. Badin et al showed that the conventional liposuction produces less reversible damage (tumefaction) than laser lipolysis with 1,000 J of energy [4]. Using energy ranging from 1,000 J up to $12,000 \mathrm{~J}$, Kim et al observed that the higher the energy, the greater the volume reduction. Typically, a $5 \mathrm{~cm}^{3}$ reduction of fat volume is observed with 3,000 J.A $20 \mathrm{~cm}^{3}$ volume reduction is obtained with $12,000 \mathrm{~J}$. All these studies show clearly that two parameters must be considered for laser lipolysis: 1) the wavelength since the interaction of the laser with the tissue is achieved by the absorption of the laser energy by the receptive chromophores, thus producing sufficient heat to cause the desired thermal damage. The heat acts of the fatty cell, the extracellular matrix to produce both reversible and irreversible cellular damage, which facilitates the liposuction through less trauma and bleeding, 2) the energy since it exists a dose-response relationship $[6,7]$.

The aim of this paper is to present a mathematical model of laser lipolysis using dynamic tissue changes based upon the Arrhenius damage model. Numerical simulations are compared to data recorded during a clinical procedure. Fat volume reduction is determined and compared to data previously reported in the literature. Theoretical understanding of laser lipolysis could help to improve the technique and optimal parameters emerging from these calculations can be taken in account to determine optimal laser dosage.

\section{Materials and Methods \\ Mathematical modeling}

An opto-thermal model of laser lipolysis consists of calculations of light distribution, temperature rise and the extent of thermal damage. The following sections describe the manner in which each stage has been implemented in our calculations.

\section{Geometrical description of the model}

The geometry used to simulate was based on a 3D model consisting of a volume of tissue with two different layers: a dermal layer (thickness: $2 \mathrm{~mm}$ ) and a hypodermis layer (thickness: $20 \mathrm{~mm}$ ). The dimensions of this volume were $14 \mathrm{~cm} \times 14 \mathrm{~cm} \times 2.2 \mathrm{~cm}$. This volume was surrounded by infinite and homogenous tissue (Figure 1). Calculations were performed for different positions of the laser cannula containing fiber optic inside this volume.

The laser lipolysis model used was based on the technique performed by the surgeon during submental laser lipolysis (Figures 2a \&2b). Four different steps were identified: \#1 - the cannula is inserted inside the hypodermis layer at approximately $0.8 \mathrm{~cm}$ below the surface, \#2 - this cannula 


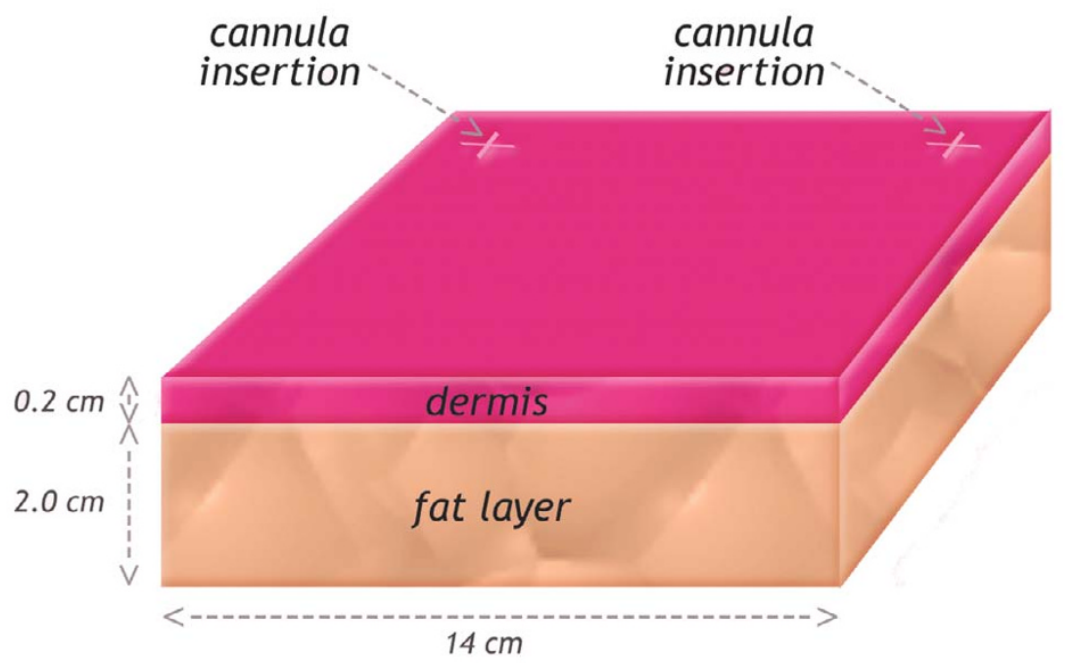

\section{Figure I}

Model geometry: 3D model consisting of a volume of tissue with two different layers: a dermal layer (thickness: $2 \mathrm{~mm}$ ) and a hypodermis layer (thickness: $20 \mathrm{~mm}$ ). The dimensions of this volume were $14 \mathrm{~cm} \times 14 \mathrm{~cm} \times 2.2 \mathrm{~cm}$. This volume is s surrounded by infinite and homogenous tissue

is moved back and forth onto $100 \mathrm{~mm}$ in the fat layer with a velocity of $100 \mathrm{~mm} / \mathrm{s}$ in a plane parallel to the surface. This back and forth motion is repeated 15 times for each position of the cannula. \#3 - the angle of the cannula is oriented in the same plane but its angle is modified to cover an angle of 90 degrees. This step is repeated 9 times (10 degrees angle each time). \#4 - in order to provide an homogeneous treatment of the fat layer, the cannula is inserted at a distance of $120 \mathrm{~mm}$ from the previous insertion point and steps \#2, and \#3 are repeated a second time.

\section{Cannula position}

The displacement $\mathrm{d}$ of the canula in each angular position is described by the following equation:

$$
d=a \times\left|\sin ^{-1}\left(\cos \left(\frac{\boldsymbol{p} \cdot t}{T}-\boldsymbol{p}\right)\right)\right|
$$

Where:
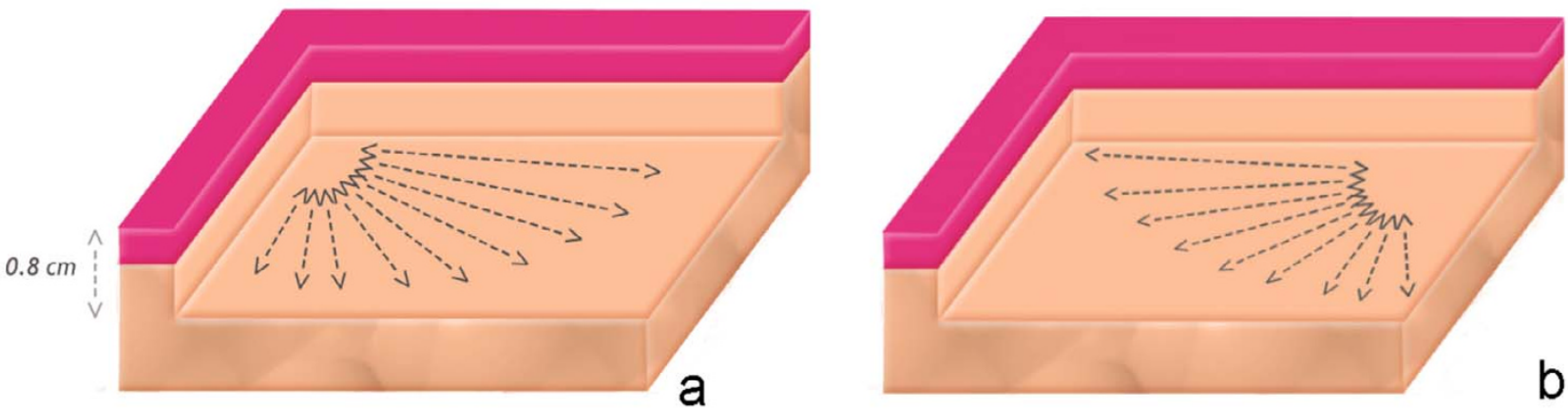

\section{Figure 2}

a: Model geometry: The cannula is inserted inside the hypodermis layer at approximately $0.8 \mathrm{~cm}$ below the surface. This cannula is moved back and forth onto $100 \mathrm{~mm}$ in the fat layer with a velocity of $100 \mathrm{~mm} / \mathrm{in}$ a plane parallel to the surface. This back and forth motion is repeated 15 times for each position of the cannula. This step is repeated 9 times ( 10 degrees angle each time). $\mathbf{2 b}$ : in order to provide a homogeneous treatment of the fat layer, the cannula is inserted at a distance of 120 mm from the previous insertion point and the procedure is repeated. 
$\mathrm{T}(\mathrm{s})$ : period of each back and forth motion (2 s)

So $y_{\text {inc }}$ and $x_{\text {inc }}$ is calculated at each time step with the following equation:

$$
\begin{aligned}
& x_{i n c}=d \times \sin \left(\boldsymbol{q}+\frac{\boldsymbol{p}}{2}\right) \\
& y_{i n c}=d \times \cos \left(\boldsymbol{q}+\frac{\boldsymbol{p}}{2}\right)
\end{aligned}
$$

Where:

$\theta\left({ }^{\circ}\right)$ : angular position incremented of $10^{\circ}$ each $30 \mathrm{~s}$.

In order to obtain reproducible results, the surgeon was asked to follow the four different steps described into the protocol. Thanks to conventional video imaging and infrared video imaging, it was possible to ensure that the different steps were effectively performed properly.

\section{Light distribution in tissue}

The light emitted from the fiber inserted the fat layer was modeled as an isotropically radiating point source. As previously proposed by Lizuka et al, spatial distribution has been considered to be dominated by scattering processes [8]. The light irradiance rate (W. $\mathrm{mm}^{-2}$ ) of an isotropic point source emitting $\mathrm{P}_{\text {laser }}(\mathrm{W})$ within an infinite homogeneous medium can be expressed as

$$
\boldsymbol{f}(r, t)=\frac{P_{\text {Laser }} \exp (- \text { eff } r)}{4 \boldsymbol{p} D r}
$$

where: $P_{\text {Laser }}(\mathrm{W})$ : power of the light source

$\mu_{e f f}\left(\mathrm{~mm}^{-1}\right)$ : effective attenuation coefficient

$r(\mathrm{~mm})$ : radial distance from the source

$D$ (mm): optical diffusion distance

$\mu_{e f f}$ is determined by the following equation

$$
\mu_{\text {eff }}=\sqrt{3 \mu_{a}\left(\mu_{a}+\mu_{s}^{\prime}\right)}
$$

where $\mu_{a}\left(\mathrm{~mm}^{-1}\right)$ : absorption coefficient in tissue

$\mu_{s}^{\prime}\left(\mathrm{mm}^{-1}\right)$ : reduced scattering coefficient: $\mu_{s}^{\prime}=\mu_{s}(1-g)$

$\mu_{s}\left(\mathrm{~mm}^{-1}\right)$ : scattering coefficient

$g$ : anisotropy factor incorporating the effects of directionally dependent scattering.

$D(\mathrm{~mm})$ is determined by the following equation:

$$
D=\frac{1}{3\left(a^{+}{ }^{\prime}\right)}=\frac{a}{\text { eff }}
$$

$r$ is defined by the following equation

$$
r=\sqrt{\left(x^{2}+y^{2}+z^{2}\right)}
$$

Where: $\mathrm{x}, \mathrm{y}(\mathrm{mm})$ : transverse dimensions

$\mathrm{z}(\mathrm{mm})$ : depth

The absorbed power density (W. $\left.\mathrm{mm}^{-3}\right)$ is expressed as follows (Welch 1984):

$$
P_{a b s}=\mu_{a} \phi(r)
$$

The laser irradiation always begins at coordinates $(0,0)$ in Figure 1 . The relative position of the cannula inside the fat layer is given by:

$$
x^{\prime}=x-x_{i n c} \text { and } y^{\prime}=y-y_{i n c}
$$

Where: $z_{\text {inc }}(\mathrm{mm})$ is the absolute position of the cannula inside the fat layer. The position of cannula is calculated for by taking into account the velocity $(\mathrm{mm} / \mathrm{s})$ during the back and forth motion. The relative position of the cannula is obtained by taking into account the cannula velocity:

$$
x_{i n c}=t \times v \text { and } y_{i n c}=t \times v
$$

where: $\mathrm{v}\left(\mathrm{mm} \cdot \mathrm{s}^{-1}\right)$ is the velocity of the back and forth motion of the cannula inside the fat layer.

\section{Calculation of temperature rise}

Absorption of light in tissue causes a local elevation in temperature. Tissue heat transfer due to the deposited light is described by the following bioheat transfer equation

$$
\nabla \cdot k \cdot \nabla T(r, t)+P_{a b s}(r, t)-w_{b} C_{p} \cdot\left[T(r, t)-T_{a r t}\right]=C_{p} \frac{\partial T(r, t)}{\partial t}
$$

Where

$T(r, t)$ : temperature $\left({ }^{\circ} \mathrm{K}\right)$

$\rho$ : density of tissue $\left(\mathrm{g} \mathrm{mm}^{-3}\right)$

C: specific heat of tissue $\left(\mathrm{J} . \mathrm{g}^{-1} \cdot{ }^{\circ} \mathrm{K}^{-1}\right)$

$C_{p}=C \cdot \rho$ : heat capacity $\left(\mathrm{J} \cdot \mathrm{mm}^{-3} \cdot{ }^{\circ} \mathrm{K}^{-1}\right)$ 
$k=$ thermal conductivity of tissue (W. $\mathrm{mm}^{-1} \cdot{ }^{\circ} \mathrm{K}^{-1}$ )

$r=$ radial distance $(\mathrm{mm})$

$t=$ time (s)

Values used for calculation are reported in Table 1

Convection of the skin surface was calculated using the following equation

$$
\varnothing_{\mathrm{Conv}}=\mathrm{hS} \Delta \mathrm{T}
$$

$\varnothing_{\text {Conv }}:$ heat flux through the surface (W)

h: convection coefficient $\left(\mathrm{W} \cdot \mathrm{m}^{-2} \cdot{ }^{\circ} \mathrm{K}^{-1}\right)$

S: Surface of the interface $\left(\mathrm{m}^{2}\right)$

$\Delta \mathrm{T}$ : difference between the inner and the outer temperature $\left({ }^{\circ} \mathrm{K}\right)$

Boundary conditions for the other surfaces were

$$
\vec{n} \cdot k \nabla T=0
$$

$\vec{n}$ : direction of the heat flux

$\mathrm{k}$ : thermal conductivity

\section{Damage function}

Thermal damage in cells and tissue can be described mathematically by a first-order thermal-chemical rate equation, in which temperature history determines damage. Damage is considered to be a unimolecular process, where native molecules transform into a denatured/coagulated state through an activated state leading to cell death. Damage is quantified using a single parameter $\Omega$, which ranges on the entire positive real axis and is calculated from the Arrhenius law [9]. Damage $\Omega$ is dimensionless, exponentially dependent on temperature, and linearly dependent on time of exposure.

$$
\log (\Omega)=\log (A)+\log \left(\int_{0}^{\infty} \exp \left(\frac{-E a}{R T(r, t)}\right) d t\right)
$$

Where $A\left(\mathrm{~s}^{-1}\right)$ is the frequency factor,

$E_{a}\left(\mathrm{~J} . \mathrm{mole}^{-1}\right)$ is the activation energy,

\begin{tabular}{|c|c|c|c|}
\hline & & Hypodermis & Dermis \\
\hline \multirow[t]{6}{*}{ Optical coefficients [17-20] } & $\mu_{a}\left(\mathrm{~mm}^{-1}\right)$ & 0.1 & 0.04 \\
\hline & $\mu_{s}\left(\mathrm{~mm}^{-1}\right)$ & 9 & 17 \\
\hline & $\mu_{s}^{\prime}\left(\mathrm{mm}^{-1}\right)$ & 0.81 & 1.53 \\
\hline & g native & 0.91 & 0.91 \\
\hline & $\mu_{\mathrm{eff}}\left(\mathrm{mm}^{-1}\right)$ & 0.52 & 0.43 \\
\hline & $\mathrm{D}(\mathrm{mm})$ & 0.36 & 0.21 \\
\hline \multirow[t]{6}{*}{ Thermal coefficients [2I-23] } & $C\left(\mathrm{~J} \cdot \mathrm{g}^{-1} \cdot \mathrm{K}^{-1}\right)$ & 2.87 & 3.3 \\
\hline & $\rho\left(\mathrm{g} \cdot \mathrm{mm}^{-3}\right)$ & $0.86 .10^{-3}$ & $1.2 .10^{-3}$ \\
\hline & $k\left(\mathrm{~W} \cdot \mathrm{mm}^{-1} \cdot \mathrm{K}^{-1}\right)$ & 3.02.1 $0^{-4}$ & 4.4.1 $10^{-4}$ \\
\hline & $\mathrm{wb}\left(\mathrm{ml} \cdot 100 \mathrm{~g}^{-1} \cdot \mathrm{min}^{-1}\right)$ & 21 & - \\
\hline & wb $\left(\mathrm{g} \cdot \mathrm{mm}^{-3} \cdot \mathrm{s}^{-1}\right)$ & 3.5.10-6 & - \\
\hline & $\mathrm{h}\left(\mathrm{W} \cdot \mathrm{m}^{-2} \cdot \mathrm{K}^{-1}\right)$ & - & 15 \\
\hline \multicolumn{4}{|l|}{ Tissue Damage Coefficients [II] } \\
\hline & $\mathrm{E}_{\mathrm{a}}\left(\mathrm{J} \cdot \mathrm{mol}^{-1}\right)$ & 6.28.1 $10^{5}$ & 6.28.1 $10^{5}$ \\
\hline & $A\left(s^{-1}\right)$ & $3.1 .10^{98}$ & 3.1.1098 \\
\hline
\end{tabular}

$R\left(\mathrm{~J} . \mathrm{mole}^{-1} \cdot{ }^{\circ} \mathrm{K}^{-1}\right)$ is the universal gas constant,

Table I: listing of physical parameters used for numerical simulation

- $\mu_{a}\left(\mathrm{~mm}^{-1}\right)$ : absorption coefficient in tissue,

- $\mu_{\mathrm{s}}\left(\mathrm{mm}^{-1}\right)$ : scattering coefficient

- $\mu_{s}^{\prime}\left(\mathrm{mm}^{-1}\right)$ : reduced scattering coefficient: $\mu_{s}^{\prime}=\mu_{s}(1-g)$

- g: anisotropy factor $\mu_{\text {eff }}\left(\mathrm{mm}^{-1}\right)$ :

- $\mu_{\text {eff }}$ effective attenuation coefficient,

- D (mm): optical diffusion distance

- C: specific heat of tissue $\left(0 . g^{-1} .^{\circ} \mathrm{K}^{-1}\right)$

- $\rho$ : density of tissue $\left(\mathrm{g} \mathrm{mm}^{-3}\right)$

- $k$ : thermal conductivity of tissue (W. $\left.\mathrm{mm}^{-1} .{ }^{\circ} \mathrm{K}^{-1}\right)$

- wb: blood flow rate (ml. $\left.100 \mathrm{~g}^{-1} \cdot \mathrm{min}^{-1}\right)$

- $\mathrm{h}$ heat-transfer coefficient $\left(\mathrm{W} \cdot \mathrm{m}^{-2} \cdot \mathrm{K}^{-1}\right.$ )

- $E_{a}$ (J.mole-1): activation energy

- $A\left(s^{-1}\right)$ : frequency factor 
$T\left({ }^{\circ} \mathrm{K}\right)$ is the temperature.

Damage $\Omega$ is a parameter that is reflective of the extent of damage. A is a frequency factor that describes how often a change in configuration actually occurs when such a reaction is energetically possible, which is also very dependent on molecular structure.

The equation indicates that the measure of damage describes the probability of tissue being destroyed. It is the logarithm of the ratio of the initial concentration of undamaged tissue to the concentration once damage has accumulated, for the time interval $\mathrm{t}=0$ to $\mathrm{t}=\tau$. Therefore, $\Omega=1$ corresponds to an irreversible damage of $100 \%$ of the affected cells.

Because the lipid bilayer components of the cell membranes are held together only by forces of hydratation, the lipid bilayer is the most vulnerable to heat damage. Even at temperatures of only $6^{\circ} \mathrm{C}$ above normal (i.e. $43^{\circ} \mathrm{C}$ ), the structural integrity of the lipid bilayer is lost [10].

In accordance to previous studies, an activation energy equals to $628 \mathrm{KJ} / \mathrm{mol}$ and a frequency factor A equals to $3.1 \mathrm{e}^{98} \mathrm{~s}^{-1}$ were used in our numerical model for cell membrane lysis [11]

\section{Numerical implementation}

The numerical simulation model was constructed with COMSOL Mutiphysics (COMSOL, Grenoble, France). Using this software, light distribution, bioheat transfer and damage function were solved simultaneously using the finite element method.

An irregular $10 \times 60$ finite element grid was used. The time steps were $0.1 \mathrm{~s}$. The tolerances used to converge the solution were $10^{-3}$. The initial temperature was set at $30.4^{\circ} \mathrm{C}$ since injection of cooled tumescent anesthetics inside the treated volume was performed.

For numerical simulations, parameters commonly used for laser lipolysis were used. Two different wavelengths: $980 \mathrm{~nm}$ and $1064 \mathrm{~nm}$ were evaluated (power: $6 \mathrm{~W}$ ), a 400 $\mu \mathrm{m}$ laser fiber introduced in a $1 \mathrm{~mm}$ cannula was considered for calculation. The listing of physical parameters used for numerical simulation is reported in Table 1.

Thanks to the numerical simulation, the surface temperature during the laser lipolysis treatment was determined for the different set of parameters and was compared to the surface temperature measured during a clinical procedure with an infrared camera. Several studies have suggested that that the total energy applied in a volume of tissue is the major determinant of treatment outcome in terms of percent reduction of fat volume [6]. In order to compare the results obtained through mathematical modeling, the total energy versus fat volume reduction was calculated.

\section{Laser procedure}

Submental laser lipolysis was performed in one patient in order: 1) to obtain a better understanding of the procedure, in particular on the position and movement of the laser cannula during the procedure, 2) to perform surface temperature measurements during the procedure, 3) to compare two different lasers used for laser lipolysis: a 1064 nm Nd:YAG laser (Smartlipo, Deka, Calenzano, Italy) and a $980 \mathrm{~nm}$ diode laser (Pharaon, Osyris, Hellemmes, France).

After obtention of the authorization of the ethical committee, and the informed consent of the patient, laserlipolysis was performed by one of the author (JPR). During this procedure, a mean power of $6 \mathrm{~W}$ was used for both lasers. The $400 \mu \mathrm{m}$ laser fiber was inserted inside a 1 $\mathrm{mm}$ cannula (Unimed, Lausanne, Switzerland) The procedure was performed after injection of tumescent anesthesia. Duplex control (Aloka 3500, Decines, France) was used to guide injection of 7-8 mL aliquots of the following solution: $10 \mathrm{ml}$ lidocaine $1 \%$ with epinephrine and $10 \mathrm{ml}$ lidocaine $1 \%$ without epinephrine and additional $60 \mathrm{ml}$ physiologic serum. The injections were performed into the facial space.

\section{Video recording}

Video recording of a submental laser lipolysis was performed using a color video camera $500 \times 582$ pixels (Model 802P, Radiospares, Beauvais, France). Video recordings were analyzed off line in order to know: 1) the position of the insertion point, 2) the different positions of the cannula during the procedure, 3 ) the velocity of back and forth movement of the cannula. These data were used for mathematical modeling.

\section{Infrared video imaging}

Infrared video imaging was used to measure the skin surface temperature during laser lipolysis. The skin surface temperature distribution was compared to mathematical modeling of skin temperature elevation following laser lipolysis [12]. An infrared camera (ThermaCAM ${ }^{\mathrm{TM}}$ A20, Flir systems $^{\mathrm{TM}}$, Issy-Les-Moulineaux, France), mounted with a macro lens giving a $34^{\circ} \times 25^{\circ}$ view angle, was used. This camera detected temperature differences as small as $0.10^{\circ} \mathrm{C}$ in a range from $-20^{\circ} \mathrm{C}$ up to $+900^{\circ} \mathrm{C}$ and produced high-resolution images $(160 \times 120$ pixels $)$. The camera was positioned at a distance of $30 \mathrm{~cm}$ from the skin surface allowing infrared imaging of a $20 \mathrm{~cm} \times 20 \mathrm{~cm}$ area. The recorded surface temperature were compared to those determined by numerical simulation using similar set of laser parameters. 


\section{Quantification of volume}

In order to assess the reduction of volume of the submentum after laser lipolysis, volume reduction was determined using a technique similar to the technique described by Lowe et al. [13]

\section{Results \\ Video recordings}

Movie01 shows a laser lipolysis procedure of the submental area [see Additional file 1]. Under cooled tumescent anesthesia, a $1 \mathrm{~mm}$ cannula was inserted inside the hypodermis layer at approximately $0.8 \mathrm{~cm}$ below the surface (step \#1). The surgeon was able to see where the end of the cannula is at all times due to the visible red light of the aiming beam that shined through the skin. This cannula was moved back and forth onto $100 \mathrm{~mm}$ in the fat layer with a velocity of $100 \mathrm{~mm} / \mathrm{s}$ in a plane parallel to the surface. This back and forth motion was repeated 15 times (step \#2). Then, the surgeon oriented of the cannula in the same plane but with a different angle (+ 10 degrees). This back and forth motion was repeated again 15 times. This step was repeated 9 times (10 degrees angle each time) to cover the entire area (step \#3). In order to provide a homogeneous treatment of the fat layer, the cannula was removed and was inserted again at a distance of $120 \mathrm{~mm}$ from the previous insertion point and steps \#2, and \#3 were repeated a second time.

\section{Infrared video recordings: surface temperature}

Movie01 shows in a different window the infrared video recording of the laser lipolysis of the submental area [see Additional file 1]. The influence of cooled tumescent anesthesia can be clearly seen at the beginning of the procedure. Surface skin temperature was reduced down to $30^{\circ} \mathrm{C}$ (Figure 3).

Movie02 shows the infrared video recording of the surface temperature during 980 nm-laser [see Additional file 2]. In another window, numerical simulation performed with the same laser parameters (980 nm diode laser, power: $6 \mathrm{~W}, \mathrm{CW}$, back and forth motion: $100 \mathrm{~mm} / \mathrm{s}$ ) is displayed (Figure 4). Mathematical modeling of surface temperature appears to be similar to surface temperature recorded during laser lipolysis of the submentum.

Using these data, it is possible to trace for a given position the maximum measured temperature and the temperature determined by mathematical modeling. For both $980 \mathrm{~nm}$ and $1064 \mathrm{~nm}$, (Figures 5 and 6), it appears clearly that they are comparable. In Figure 5, one can observe that at the time range of $550 \sim 850 \mathrm{~s}$, laser energy increases, but the maximum temperature obtained from simulation fluctuates. The explanation is the following:

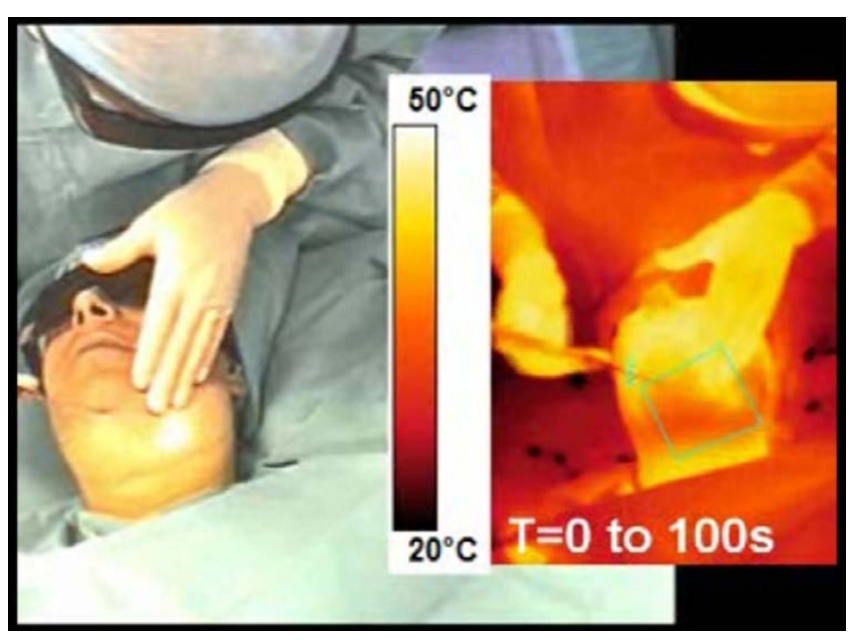

Figure 3

video recording of a laser lipolysis procedure inside the submentum. Conventional and infrared video recordings are performed simultaneously.

The cannula is moved back and forth onto $100 \mathrm{~mm}$ in the fat layer during the laser lipolysis procedure. Consequently, for a given location (here the maximum temperature recorded during the complete treatment of the fat volume), the maximum temperature decreases. However, when the surgeon moves the cannula to a new position, heat transfer leads to an increase temperature in the vicinity of the previous position. The maximum surface temperature never exceeded $41^{\circ} \mathrm{C}$.

\section{Total energy versus fat volume reduction}

Laser irradiation induces a progressive built up of the temperature and consequently thermal damage is observed. The volume of tissue where thermal damaged $(\Omega \geq 1)$ was considered to determine the fat volume reduction.

At the end of the procedure, for $980 \mathrm{~nm}$, a total energy of $3500 \mathrm{~J}$ is delivered. The volume for which $\Omega \geq 1$ is $4.3 \mathrm{~cm}^{3}$. (Figure 7) For $1064 \mathrm{~nm}$, a total energy of $3100 \mathrm{~J}$ is delivered. The calculated volume reduction is $2.6 \mathrm{~cm}^{3}$ (Figure $8)$. The fact that the cannula was not reciprocated exactly the same way in the left $(980 \mathrm{~nm})$ and the right (1064 $\mathrm{nm}$ ) side of the submentum easily explains this difference due to a lower energy in the right side. Besides the fat volume reduction due to temperature elevation, the volume reduction due to the mechanical insertion and back and forth motion inside the fat layer must be considered. Each fiber insertion during the back and forth motion creates a mechanical damage along the fiber with a resulting channel. This channel is even produced without firing the laser. When considering the total number of channels created by the back and forth motion of a $400 \mu \mathrm{m}$ fiber, an 


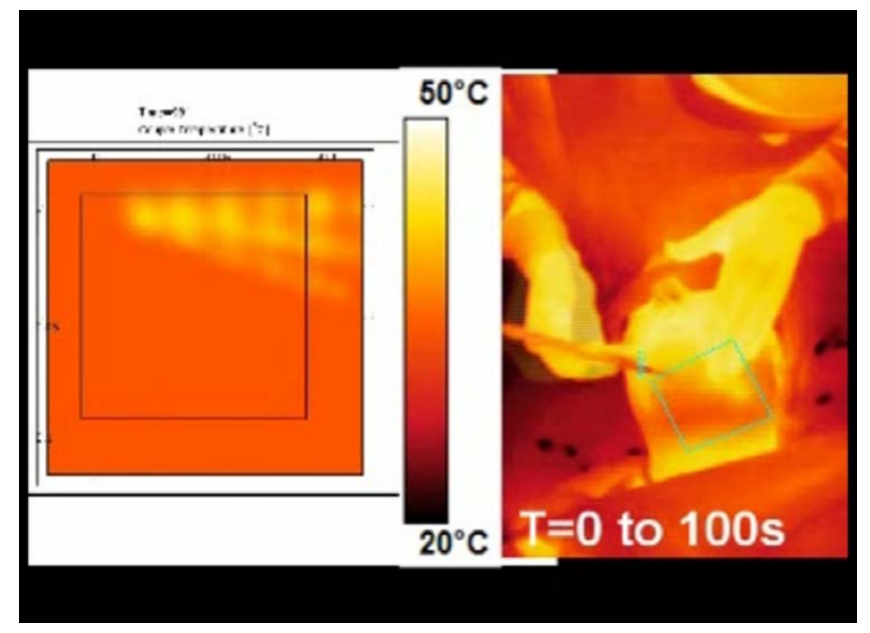

Figure 4

infrared video recording of a laser lipolysis procedure inside the submentum (right) and mathematical modeling performed of a specific area (green square of submentum of the patient).

additional $3.5 \mathrm{~cm}^{3}$ must be added to the fat volume reduction induced by heating.

Consequently thermal and mechanical damages leads to a total volume reduction of $10.4 \mathrm{~cm}^{3}$.
This volume was compared to the fat volume reduction obtained in this patient 6 months after laser lipolysis. Before and 6-month follow up pictures were used to quantify the fat volume reduction (Figures 9a, b, c, d). Using these calibrated images, volume reduction was calculated. A $10 \mathrm{~cm}^{3} \pm 1 \mathrm{~cm}^{3}$ volume reduction was obtained.

At 6 month-follow up, skin tightening was also observed. Since this mechanism was already described using nonablative laser remodeling, numerical simulation was performed to know the temperature distribution inside the skin layer.

\section{Temperature distribution inside the skin layer}

The temperature distribution inside the skin layer is displayed in Figure 10. Due to heat diffusion from the fat layer, the dermis and the epidermis are also heated. The temperatures reached inside the lower dermis $(1.5 \mathrm{~mm})$ and the reticular dermis $(0.5 \mathrm{~mm})$ are respectively $44^{\circ} \mathrm{C}$ and $42^{\circ} \mathrm{C}$. The temperature calculated at the surface of the epidermis $\left(41^{\circ} \mathrm{C}\right)$ is in agreement with that measured by the infrared camera.

\section{Discussion}

Laser lipolysis is a new technique still under development. The main objectives of this technique are faster recovery, less operator effort and skin tightening [7]. The use of the $1064 \mathrm{~nm}-\mathrm{Nd}$ :YAG laser and the 980-nm diode laser as an auxiliary tool has refined the traditional lipoplasty tech-

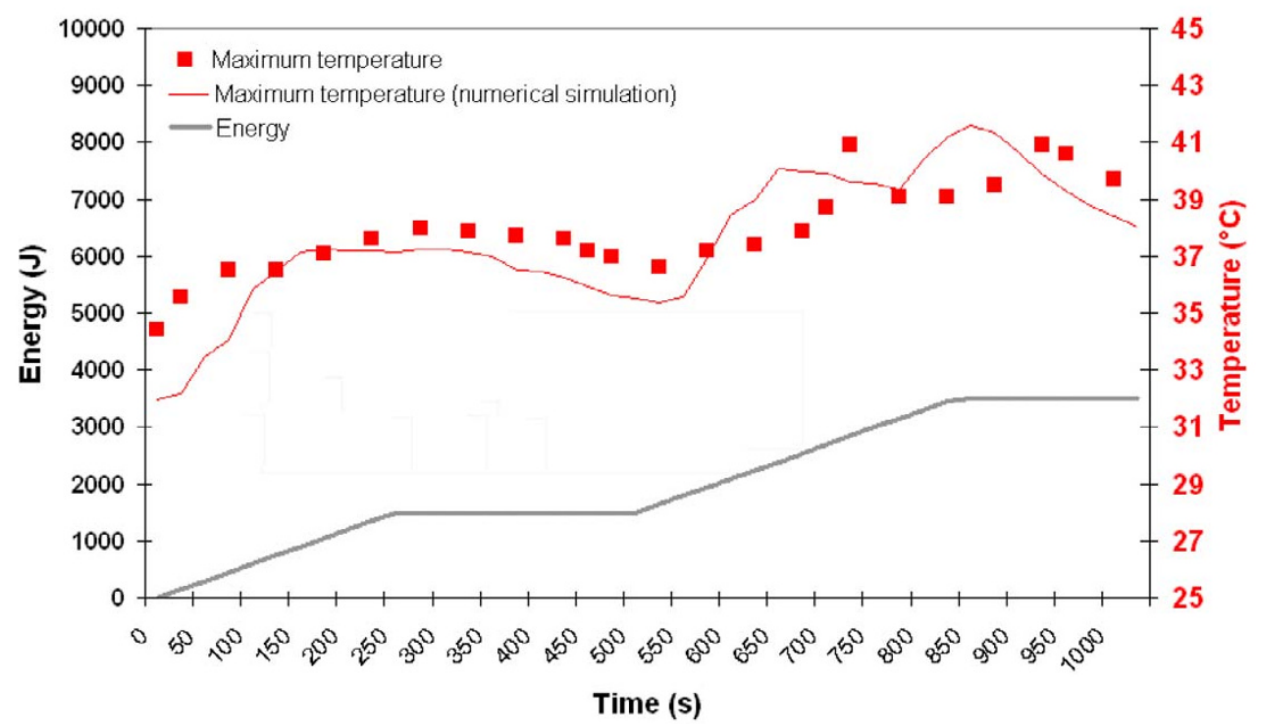

\section{Figure 5}

Maximum temperature recorded on skin surface (red square) using the infrared camera and determined at the same position by numerical simulation (red line) as a function time and energy. The energy delivery as function of time is traced (gray line). Right side: $980 \mathrm{~nm}$ diode laser, power: $6 \mathrm{~W}, \mathrm{CW}$, back and forth motion: $100 \mathrm{~mm} / \mathrm{s}$ ). 


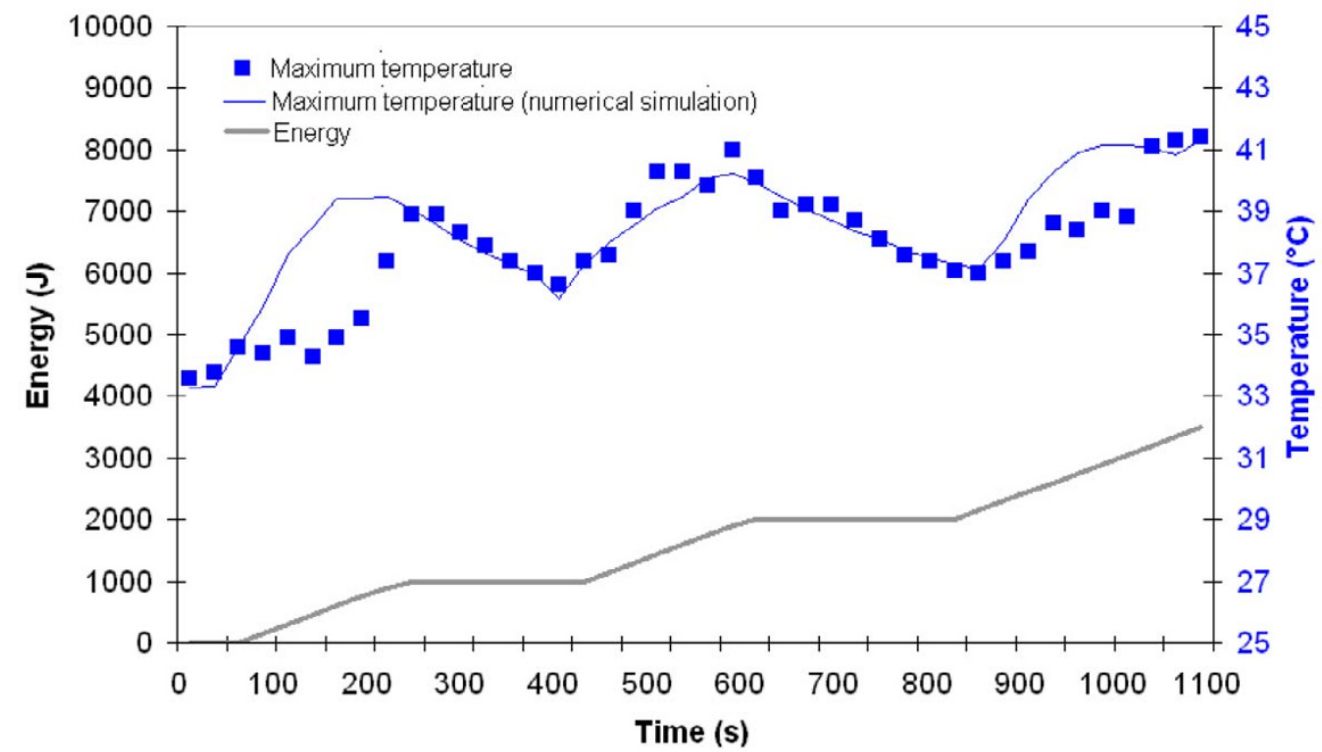

\section{Figure 6}

Maximum temperature recorded on skin surface (blue square) using the infrared camera and determined at the same position by numerical simulation (blue line) as a function time and energy The energy delivery as function of time is traced (gray line). Left side: $1064 \mathrm{~nm} \mathrm{Nd:YAG} \mathrm{laser,} \mathrm{power:} \mathrm{6W,} \mathrm{CW,} \mathrm{back} \mathrm{and} \mathrm{forth} \mathrm{motion:} 100 \mathrm{~mm} / \mathrm{s}$ ).

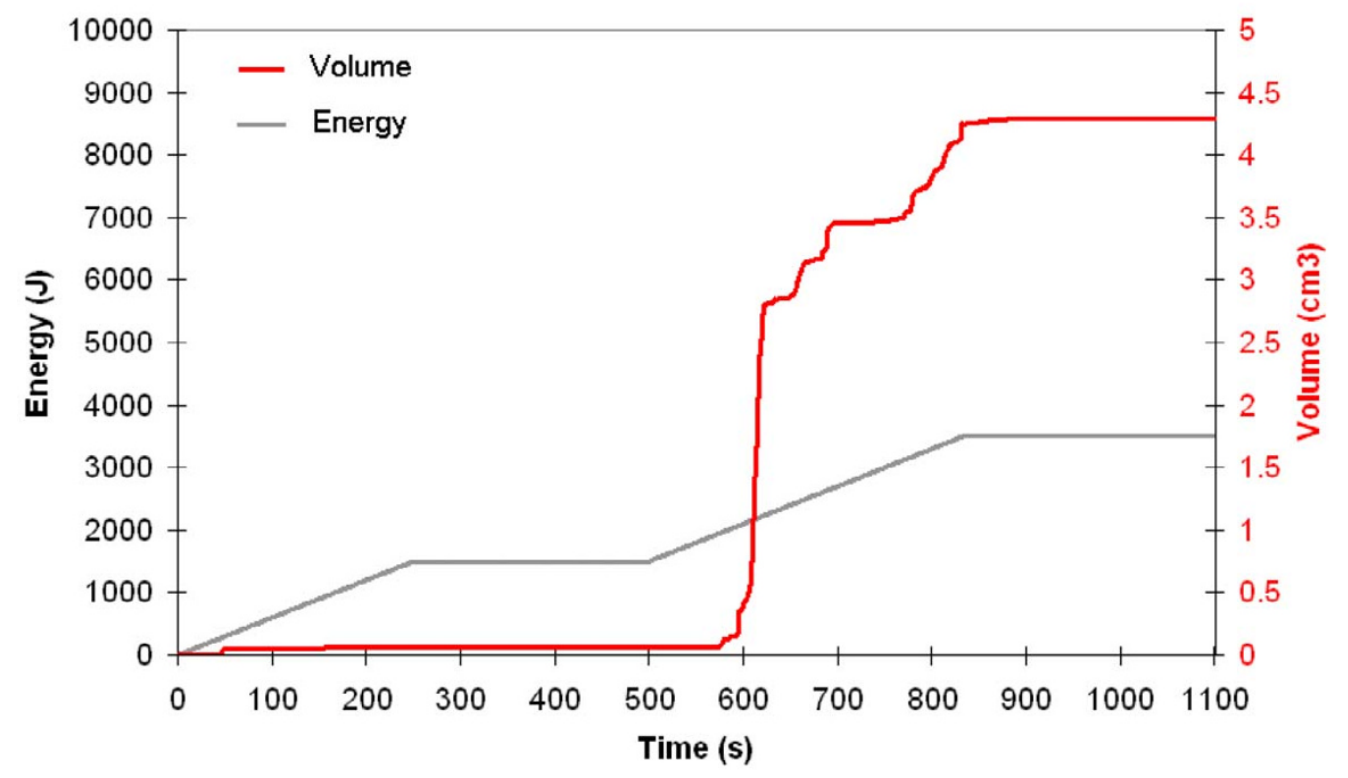

\section{Figure 7}

Volume reduction (red line) determined by numerical simulation as a function time and energy ( $980 \mathrm{~nm}$-diode laser). The energy delivery as function of time is traced (gray line). Right side: $980 \mathrm{~nm}$ diode laser, power: $6 \mathrm{~W}$, CW, back and forth motion: $100 \mathrm{~mm} / \mathrm{s}$. 


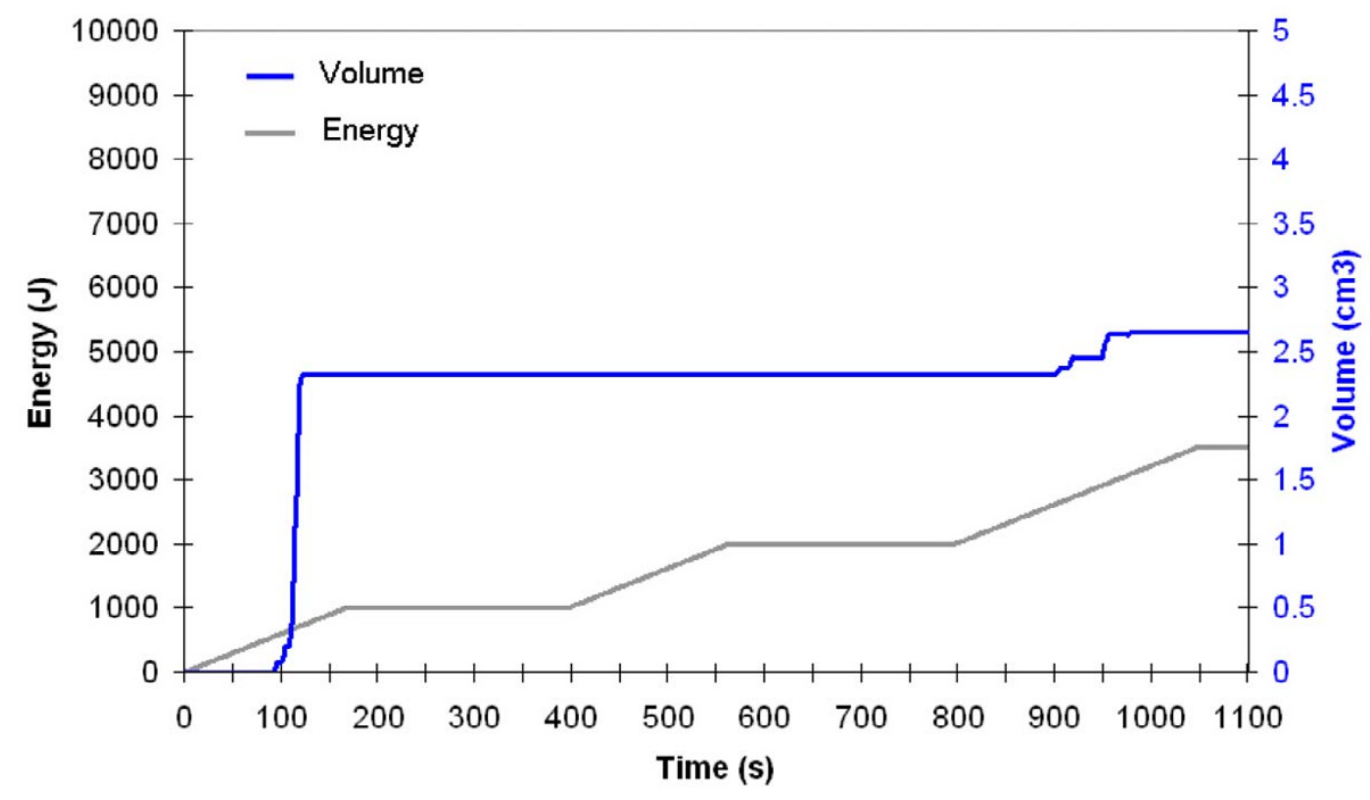

Figure 8

Volume reduction (blue line) determined by numerical simulation as a function time and energy. The energy delivery as function of time is traced (gray line). Left side: $1064 \mathrm{~nm} \mathrm{Nd:YAG} \mathrm{laser,} \mathrm{power:} \mathrm{6W,} \mathrm{CW,} \mathrm{back} \mathrm{and} \mathrm{forth} \mathrm{motion:} 100 \mathrm{~mm} / \mathrm{s}$ ).

nique. Under anaesthesia, a small puncture or incision is made in the skin and the laser light is conveyed through the insertion of a micro-cannula (with a diameter of 1 $\mathrm{mm}$ ) into which an optical fibre has been inserted. The surgeon is able to see where the end of the cannula is at all times due to a visible red light of the aiming beam that shines through the skin. The surgeon can then move the cannula back and forth and laterally to effectively and evenly liquefy the fat in the treatment area. Due to the small size of cannulas used $(1 \mathrm{~mm})$ this liposculpture treatment is considered to be minimally invasive when compared to traditional liposuction techniques, meaning that delicate areas such as the face, forearms, upper abdomen and knees can be treated using this method. The fat is then disposed of via the body's natural processes.

The interaction of the laser with the tissue is achieved by the absorption of the laser energy by the receptive chromophores, thus producing sufficient heat to cause the desired thermal damage. The heat acts on the fatty cell and, the extracellular matrix to produce both reversible and irreversible cellular damage. Several studies have demonstrated that for low energy settings and both 980 $\mathrm{nm}$ and $1064 \mathrm{~nm}$, a tumefaction of the adipocytes is observed leading to an increase of their diameter up to $100 \mu \mathrm{m}[4,5]$. The heat generated by the laser would alter the balance of sodium and potassium of the cellular membrane, allowing the free transport of extracellular liquid to the intracellular atmosphere. For higher energy settings rupture of adipocytes, coagulation of collagen fiber and small vessels are observed [3,5]. Due to the rupture of the membrane, lipases liberated by the adipocyte are responsible for the liquefaction of the tissue, which further facilitates the subsequent aspiration. Through the liquefactive effect of the laser, the back and forth movement of the cannula is performed much more easily than when performing the conventional liposuction technique. The fact that heat induces also coagulation of small vessels in the fat tissue is very important since this phenomenon facilitates the liposuction through less trauma and bleeding. Liposuction removes significant amounts of fat, serum and blood. In cases wherein large amounts of fatty tissue are to be removed, a physiologically significant loss of blood can provoke metabolic alterations. In this way, laser-assisted liposuction offers the advantage of removing larger volumes of fat without hemodynamic repercussions [4].

To date, mathematical modeling of laser lipolysis has never been proposed. This task was performed to assist in providing a better understanding of the laser lipolysis process and possibly to determine the optimal dosage as a function of the volume of fat to be removed. Our model remains a mathematical model, implying that errors may appear owing to the considerations and simplifications required to realize it. Generally, such errors appear because of inaccuracy of the optical, thermal, and damage properties that are critical points in the model's set of 


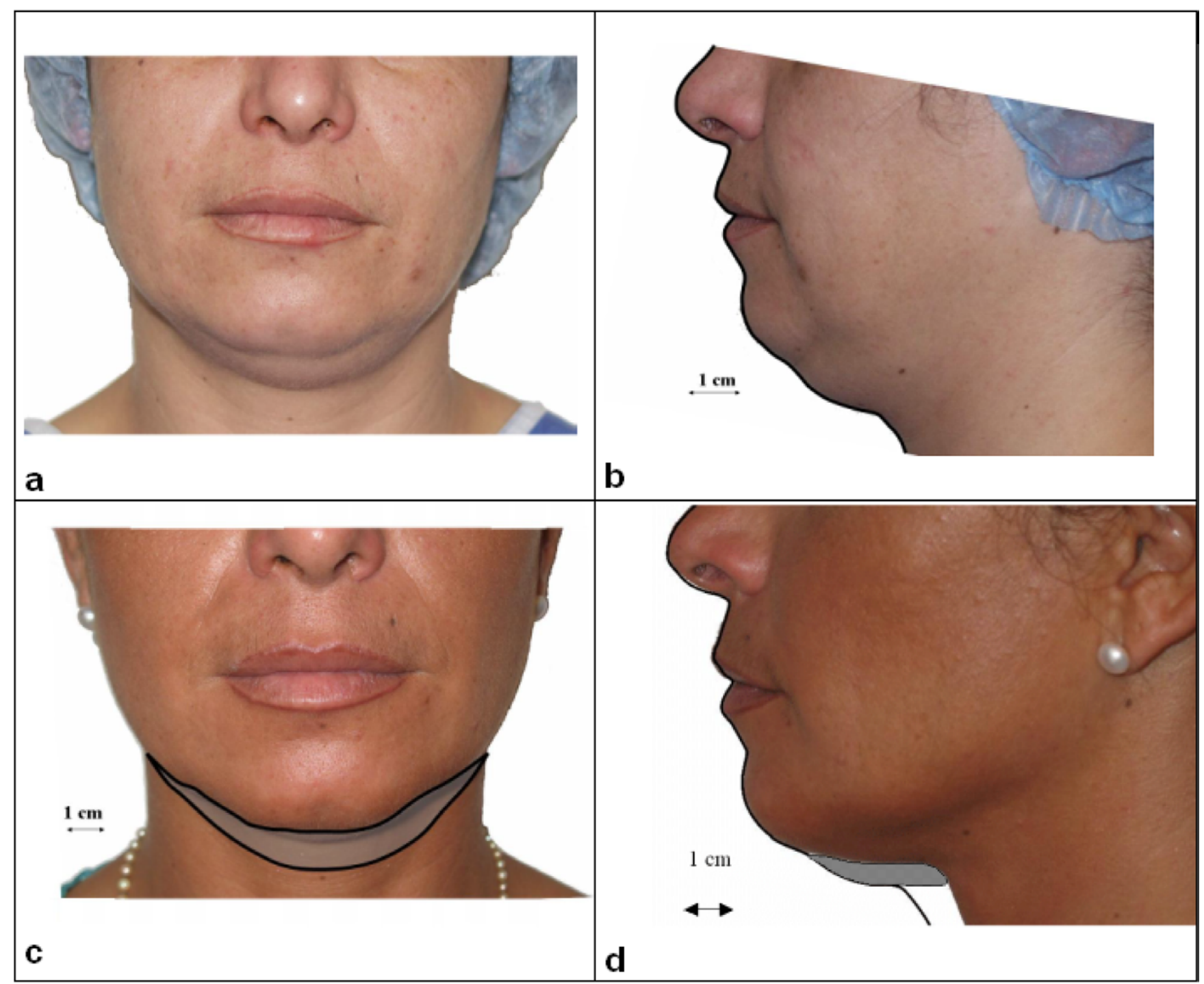

\section{Figure 9}

shows pictures of the patient before and at 6-month follow-up. - a and b: before laser lipolysis, - c and d: 6 months after laser lipolysis. Right side: $980 \mathrm{~nm}$ diode laser, power: 6W, CW, back and forth motion: $100 \mathrm{~mm} / \mathrm{s}$, total energy: $3500 \mathrm{~J})$. Left side: $1064 \mathrm{~nm}$ Nd:YAG laser, power: 6W, CW, back and forth motion: $100 \mathrm{~mm} / \mathrm{s}$, total energy: $3100 \mathrm{~J}$ )

equations. In fact, these properties play a key role in the accuracy of the results achieved. Many methods have been presented to calculate these properties but still we see differences in the values presented by the different groups, which reflect the difficulty of measuring these properties. The problem is increased by the reliance of the properties on different variables (temperature, damage) over time. This makes the deviation neither linear nor regular [9]. Moreover, it is very difficult to standardize the surgeon's technique during laser lypolysis. For, this reason and in order to compare the results of our calculations to clinical data already reported in the literature, only submental laser lipolysis was considered. Video recordings were used to gain a better understanding of the back and forth movement of the cannula during laser lipolysis (movie 01) in order to consider them in our mathematical model. Infrared video recordings were also performed in order to compare the actual surface temperatures to our calculations.

These video recordings have provided useful information on the position of cannula during laser lipolysis and in particular how this cannula is moved back and forth inside the fat layer. The parameters gained from these video recordings are comparable to those reported in the literature. For example, Ichikawa et al inserted the cannula into the target layer of the subcutaneous fat approximately 


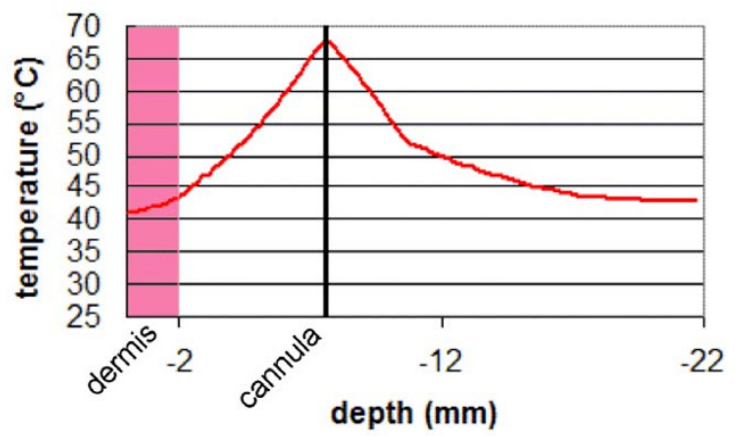

Figure 10

maximum temperature elevation recorded inside the skin during laser lipolysis. Parameters: $980 \mathrm{~nm}$ diode laser, power: $6 \mathrm{~W}, \mathrm{CW}$, back and forth motion: $100 \mathrm{~mm} / \mathrm{s}$, total energy: $3500 \mathrm{~J}$.

$1 \mathrm{~cm}$ below the skin [7]. This cannula was moved back and forth several times. The step consisted in irradiating the fat layer by using the cannula with a different angle while maintained on the same plane. Consequently, these video recordings confirm that our mathematical simulations are transposable to the surgical practice.

Before attempting to compare the parameters used for simulation to those usually reported in the literature, the following comments must be made: 1 ) to the best of our knowledge no previous publications have reported mathematical modeling of laser lipolysis 2) Several clinical papers were published. However in most of them, laser parameters in particular the total energy of a given volume are not reported. At last, if clinical before and after photographs are presented, the reduction of fat volume is usually not reported, except in one paper where magnetic Resonance Imaging before laser lipolysis and at 3-month follow-up was used to quantify this volume [6].

Besides the fat volume reduction due to temperature elevation, the volume reduction due to the mechanical insertion and back and forth motion inside the fat layer must be considered. Histologic studies have showed that a channel was produced due to fiber insertion. Rupture of adipocytes and fragments of adipose cell membrane were observed inside this channel $[3,5]$.

It is interesting to compare the parameters used in our mathematical simulations to those usually reported in the literature, for the submental zone. However only a few clinical studies were published and in most of them important data are missing. Goldman, in a clinical report on submental Nd:YAG laser lipolysis on 82 patients, observed on histology, the coagulation of small blood vessel in the fatty tissue and the rupture of adipocytes [3]. Unfortunately, no data are given on the total applied energy, and the exact fat volume reduction. Prado et al used a Nd:YAG laser and applied $400 \mathrm{~J}$ for in the submental zone [2]. Key performed submental laser lipolysis with a $1320 \mathrm{~nm}$ laser using 560 to 1040 Joules. However, for these two clinical studies, the reduction of the fat volume remained unknown. In order to quantify the reduction of the fat volume, ten patients treated by Kim et al underwent an MRI pre-procedure and 3-months after 1064 nmlaser lipolysis. Looking at the specific sites, the submentum with a baseline average volume of $20 \mathrm{~cm}^{3}$ had a greater reduction (25\%) compared with other, larger treatment sites, suggesting a dose-response relationship [6]. In the submental zone, approximately $3000 \mathrm{~J}$ was applied to get a mean volume reduction of $5.2 \pm 2.8 \mathrm{~cm}^{3}$. This is comparable to the volume reduction observed in our study: $10 \mathrm{~cm}^{3} \pm 1 \mathrm{~cm}^{3}$ for a total energy of $6600 \mathrm{~J}$.

At last, the mechanical cannulation of body fat tissues leads also to a fat volume reduction. Our calculations demonstrate that it represents one third of the total volume.

As a result, the interaction between the laser and the biological tissue produce a reduction of the volume of fat as well as remodeling of the collagenous tissue, with clinically evident skin retraction. The heating of deep reticular dermis is confirmed by the infrared measurements and by our calculations. These temperatures are comparable to those already reported when laser irradiation was performed with a non-ablative laser $[14,15]$. They induce an inflammation process inside the deeper dermis. The wound repair that follows the laser treatment leads to the creation of new collagen and elastin fibers and consequently tissue tightening. This phenomenon is confirmed by Badin et al who observed after histological analysis that the collagen denaturing performed in the deep reticular dermis and the conjunctive septum of the subcutaneous tissue constituted a proinflammatory stimulant followed by vascular proliferation and collagen neosynthesis [4]. At last, the resulting skin retraction observed on the patient confirms these claims and is in accordance to previous clinical studies $[16,6]$.

\section{Conclusion}

Laser lipolysis can be studied by numerical simulation. Temperature elevation measured on skin surface and fat volume reduction measured after treatment are comparable to those determined by calculation. The interaction between laser and the adipocytes causes lipolysis with reduced bleeding and its effects on collagen tone promote collagen retraction and skin shrinkage. It is remarkable that by means of a few simplyfing assumptions, laser lipolysis can be described by a very tractable and intuitive model. The numerical model shows a very good fit with the experimental data. This model should serve as a useful 
tool to simulate and better understand the mechanism of action of laser lipolysis

\section{Additional material}

\section{Additional file 1}

video recording of a laser lipolysis procedure inside the submentum. conventional and infrared video recordings are performed simultaneously. Parameters used during the procedure were the following: left side; 1064 $n m$ Nd:YAG laser, power: $6 \mathrm{~W}, \mathrm{CW}$, back and forth motion: $100 \mathrm{~mm} / \mathrm{s}$ right side: $980 \mathrm{~nm}$ diode laser, power: $6 \mathrm{~W}, \mathrm{CW}$, back and forth motion: $100 \mathrm{~mm} / \mathrm{s}$

Click here for file

[http://www.biomedcentral.com/content/supplementary/1475925X-7-10-S1.wmv]

\section{Additional file 2}

video recording of a laser lipolysis procedure inside the submentum. infrared video recording (right) and movie obtained by numerical simulation using the same laser parameters (left) Parameters used during the procedure were the following: $980 \mathrm{~nm}$ diode laser, power: $6 \mathrm{~W}, \mathrm{CW}$, back and forth motion: $100 \mathrm{~mm} / \mathrm{s}$. Mathematical modeling of surface temperature appears to be similar to surface temperature recorded during laser lipolysis of the submentum.

Click here for file

[http://www.biomedcentral.com/content/supplementary/1475925X-7-10-S2.wmv]

\section{References}

I. Apfelberg DB, Rosenthal S, Hunstad JP, Achauer B, Fodor PB: Progress report on multicenter study of laser-assisted liposuction. Aesthetic Plast Surg 1994, I 8(3):259-264.

2. Prado A, Andrades P, Danilla S, Leniz P, Castillo P, Gaete F: A prospective, randomized, double-blind, controlled clinical trial comparing laser-assisted lipoplasty with suction-assisted lipoplasty. Plast Reconstr Surg 2006, I I 8(4): I032- 1045.

3. Goldman A: Submental Nd:Yag laser-assisted liposuction. Lasers Surg Med 2006, 38(3): |8|-184

4. Badin AZ, Gondek LB, Garcia MJ, Valle LC, Flizikowski FB, de Noronha L: Analysis of laser lipolysis effects on human tissue samples obtained from liposuction. Aesthetic Plast Surg 2005, 29(4):28I-286.

5. Mordon S, Eymard-Maurin AF, Wassmer B, Ringot J: Histologic evaluation of laser lipolysis: Pulsed I,064nm Nd: YAG laser versus CW 980nm diode laser. Aesthetic Surgery Journal 2007, 27(3):263-268.

6. Kim KH, Geronemus RG: Laser lipolysis using a novel I,064 nm Nd:YAG Laser. Dermatol Surg 2006, 32(2):24 I-48; discussion 247.

7. Ichikawa K, Miyasaka M, Tanaka R, Tanino R, Mizukami K, Wakaki M: Histologic evaluation of the pulsed Nd:YAG laser for laser lipolysis. Lasers Surg Med 2005, 36(I):43-46.

8. lizuka $M N$, Vitkin IA, Kolios MC, Sherar MD: The effects of dynamic optical properties during interstitial laser photocoagulation. Phys Med Biol 2000, 45(5): I335- I357.

9. Mohammed $Y$, Verhey JF: A finite element method model to simulate laser interstitial thermo therapy in anatomical inhomogeneous regions. Biomed Eng Online 2005, 4(I):2

10. Moussa NA, Tell EN, Cravalho EG: Time progression of hemolysis or erythrocyte populations exposed to supraphysiologic temperatures. I Biomech Eng 1979, 10 1:213-217.

II. Pearce J, Thomsen S: Rate process analysis of thermal damage. Thermal reponse of laser irradiated tissue. Edited by: Welch AJ. New York, USA, Plenum Press; 1995.

12. Choi B, Welch AJ: Infrared imaging of 2-D temperature distribution during cryogen spray cooling. J Biomech Eng 2002, I 24(6):669-675
13. Lowe P, Lowe NJ: 3D Photography and lip filler: A novel assay - Journal of Cutaneous Laser Therapy 2007, 9(4):.

14. Muccini JA Jr., O'Donnell FE Jr., Fuller T, Reinisch L: Laser treatment of solar elastosis with epithelial preservation. Lasers Surg Med 1998, 23(3): I $21-127$

I5. Mordon S, Capon A, Creusy C, Fleurisse L, Buys B, Faucheux M, Servell $P$ : In vivo experimental evaluation of skin remodeling by using an Er: Glass laser with contact cooling. Lasers Surg Med 2000, 27(I): I-9.

16. Badin AZ, Moraes LM, Gondek L, Chiaratti MG, Canta L: Laser lipolysis: flaccidity under control. Aesthetic Plast Surg 2002, 26(5):335-339.

17. Dai T, Pikkula BM, Wang LV, Anvari B: Comparison of human skin opto-thermal response to near-infrared and visible laser irradiations: a theoretical investigation. Phys Med Biol 2004 49(2I):486I-4877.

18. Bashkatov AN, Genina EA, Kochubey VI, Tuchin VV: Optical properties of human skin, subcutaneous and mucous tissues in the wavelength range from 400 to $2000 \mathrm{~nm}$. J Phys D: Appl Phys 2005, 38:2343-2355.

19. Ichikawa K, Tanino R, Wakaki M: Histologic and photonic evaluation of a pulsed Nd:YAG laser for ablation of subcutaneous adipose tissue. Tokai J Exp Clin Med 2006, 3 I (4): | 36- | 40.

20. Salomatina E, Jiang B, Novak J, Yaroslavsky AN: Optical properties of normal and cancerous human skin in the visible and nearinfrared spectral range. I Biomed Opt 2006, I I(6):64026.

21. Giering K, Lamprecht I, Minet O: Specific heat capacities of human and animal tissues: San Jose, CA, USA. Volume 2624 Edited by: Meier GPDRWSLOSHATH. SPIE; 1996:188-197.

22. Valvano J: Tissue thermal proerties and perfusion. In Opitcalthermal response of laser irradiated tissue Edited by: Welch A. New York, NY, USA , Plenum Press; 1995.

23. Aguilar G, Majaron B, Pope K, Svaasand LO, Lavernia EJ, Nelson JS: Influence of nozzle-to-skin distance in cryogen spray cooling for dermatologic laser surgery. Lasers Surg Med 2001, 28(2): I | $3-120$.
Publish with Biomed Central and every scientist can read your work free of charge

"BioMed Central will be the most significant development for disseminating the results of biomedical research in our lifetime. "

Sir Paul Nurse, Cancer Research UK

Your research papers will be:

- available free of charge to the entire biomedical community

- peer reviewed and published immediately upon acceptance

- cited in PubMed and archived on PubMed Central

- yours - you keep the copyright
BioMedcentral 